\title{
Growth gradients in fish larvae*
}

\author{
L. A. Fuiman \\ School of Natural Resources and Great Lakes Research Division, S. T. Dana Building, \\ University of Michigan, Ann Arbor, MI 48109, U.S.A.
}

(Received 18 May 1982, Accepted I November 1982)

\begin{abstract}
Relative growth intensity of various longitudinally measured body segments in larvae of several species of fishes was distributed across the body in a continuous, $U$-shaped gradient. Juveniles lacked a simple pattern of growth but appeared to grow nearly isometrically. Body depth exhibited a shallow, $U$-shaped gradient while body width lacked a discernible pattern. Most intense growth, in three orthogonal planes, occurred posteriorly, probably promoting effective swimming early in life.
\end{abstract}

\section{INTRODUCTION}

Almost by definition, larval fishes are differently shaped from their adult counterparts, yet they assume the adult form over a short period of time. Quantitative evidence of this transformation lies in the progressive variation of morphometric proportions with increasing size, as illustrated by many current larval fish descriptions (Snyder et al., 1977; Cooper, 1978a, b; Fuiman, 1979). These morphometric changes are the result of differential relative growth (allometry).

The principles of relative growth were set forth by Huxley (1932) and only minor changes in terminology have ensued. The allometry equation, a simple power function $\left(y=b x^{k}\right)$, serves as the model for relative growth with theoretical and empirical support. A growth profile, as devised by Huxley, is a crude representation of an underlying growth gradient in an organism or part of one. In this method a growth coefficient (an estimate of growth intensity, $k$ in the model) for each segment is plotted against the location of the midpoint of its segment, arbitrarily located on the abscissa. Huxley (1932) admitted the inherent inability to assign fixed points along the abscissa because allometry causes the midpoints to shift. Further, he gave no indication of the variability associated with each growth coefficient. He did, however, recognize that growth coefficients represent mean values for large areas and that, theoretically, there is a progressive change in $k$ from point to point. The objective of this study is to determine the nature of differential growth of selected fish species during their larval period by improving the method of constructing a growth profile.

\section{MATERIALS AND METHODS}

Morphometric data were obtained from colleagues who generated them in the course of describing larval development of the following species: Catostomidae-Catostomus

${ }^{*}$ Contribution No. 350 of the Great Lakes Research Division of the University of Michigan. 
commersoni (Fuiman, 1979), C. latipinnis (Snyder, 1981); Cyprinidae-Couesius plumbeus (Fuiman \& Baker, 1981); Osmeridae-Osmerus mordax (Cooper, 1978b); Percidae-Percina caprodes (Cooper, 1978a).

Measurements made parallel to the longitudinal axis of the fish originated at the tip of the snout and ended at a designated landmark (i.e. a point homologous through development). Body segment lengths were generated by sequentially subtracting a measurement from the next larger one. Because each author used different numbers of landmarks, body segments do not exactly correspond among the species studied. Body depths and widths were measured on one species (C. latipinnis) by Snyder (1981). The various body segments, illustrated for the smallest specimens at the top of Fig. 1, were measured on a developmental series of specimens (repeated measurements were not made on individuals over time).

Use of the allometry equation requires selection of a standard representing size ( $x$ in the model). Huxley chose body length when working with fishes, thereby introducing interpretation difficulties because the standard subtends the segments. I designated eye diameter as the standard because it is a distinct organ, its functional capacity probably does not change abruptly once pigmented (prior to hatching in the species studied here), and it usually grows at a constant differential rate with respect to total length (T.L.) (Fig. 2). Points of inflection, signifying separate growth stanzas and necessitating separate analyses, were determined by examining plots of eye diameter on T.L. and segment lengths on eye diameter on a double logarithmic grid.

A growth coefficient $(k)$ and its variability, for each segment, was determined as the slope and its $95 \%$ confidence interval in the regression of log-transformed data. The location of the body segment midpoint, the independent variable of the growth profile, was estimated by its mean position from the tip of the snout, as a percentage of T.L. The range of these values was used as an indication of variability in midpoint location. Inclusion of these two variability estimators, the more accurate location of the independent variable, and the choice of a more suitable standard than body length alleviated some of the difficulties of Huxley's original method.

\section{RESULTS}

Logarithmic plots of eye diameter on T.L. exhibited only one stanza for all species, except Osmerus mordax which demonstrated two stanzas (Fig. 3). Accordingly, separate analyses were performed for these stanzas. Likewise, two stanzas were identified in logarithmic plots of body segment length on eye diameter for Catostomus commersoni and Couesius plumbeus. The second stanzas corresponded to individuals conventionally termed juveniles (complete finfold absorption and fin ray formation).

Regressions of log-transformed segment lengths on log-transformed eye diameters were nearly always significant $(P<0.05)$. Insignificant regressions were generally associated with smallest values of $k$. All segment midpoints travelled toward midbody ( $50 \%$ T.L.) with increasing size.

Growth profiles for larvae of five distantly related species shared a common U-shaped pattern [Fig. 1(a), (b), (d), (g), 4(a)]. Growth profiles for juveniles lacked a smooth gradient [Fig. 1(e), (f)]. Both stanzas in Osmerus mordax occurred within the larval period. In the first stanza [Fig. 1(c)] there was no clear pattern of growth. The subsequent stanza [Fig. 1(g)] was characterized by a U-shaped gradient as seen in the other species.

Growth profiles were also constructed for larvae of the following species using published summarized morphometric data: Clupea harengus (Ford, 1930; Huxley, 1931), Sardinops ocellata and Sprattus sprattus (Ford, 1931), Micropterus dolomieui (Doan, 1939), and Esox lucius (Franklin \& Smith, 1960). 

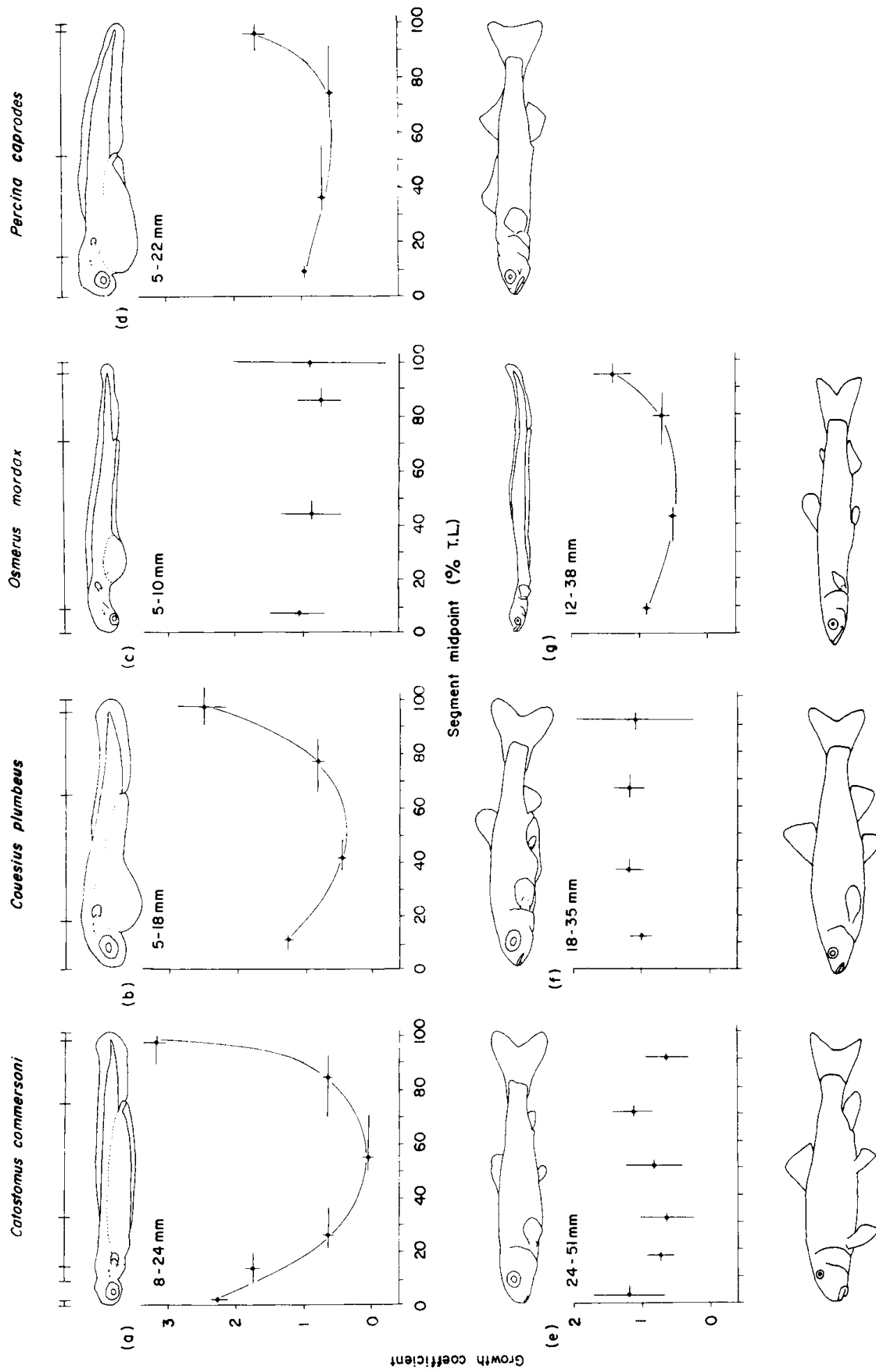

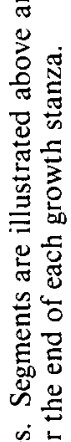

递

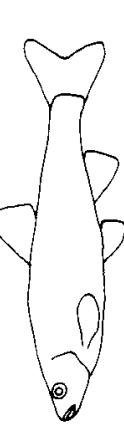

के

与

응

竞兄

品

궁

(1) $8 \overline{0}$

方

蛋

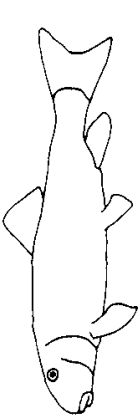

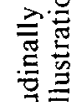

总

흥

홍

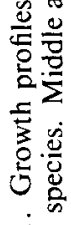

$\dot{5}$ 


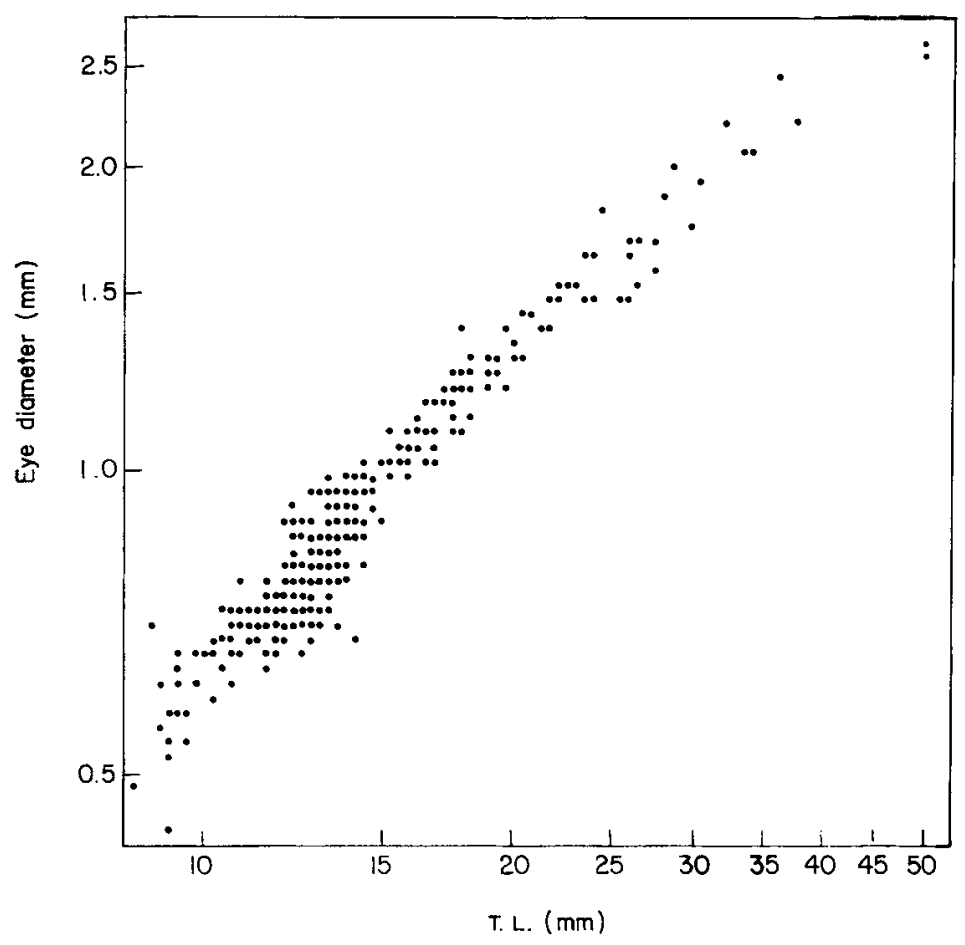

FIG. 2. Relationship between eye diameter and T.L. for Catostomus commersoni, showing the usual single growth stanza. Data are plotted on a double logarithmic grid.

The summarized nature of the data (mean proportions for arbitrary size intervals) do not permit close scrutiny of the results, however the general ' $U$ '-shape is like those for larvae discussed above.

Morphometric data for another species, Catostomus latipinnis, permitted examination of growth along the longitudinal axis and in the two orthogonal planes. Growth of segment lengths followed a U-shaped gradient [Fig. 4(a)]. Body depths demonstrated a shallow, U-shaped gradient but widths lacked a well defined gradient [Fig. 4(b)].

\section{DISCUSSION}

Growth profiles indicate that larvae grow in length differently than juveniles. In larvae, growth intensities are not distributed uniformly across the body, but in a regular pattern constituting a smooth, continuous gradient. The gradient is characterized by a period with terminal growth centres (high intensity) and a continuous, U-shaped gradient between them. Juvenile growth, as measured in the longitudinal plane, approaches isometry $(k=1)$ across the entire body. Growth probably remains nearly isometric through adulthood, based on the small amount of shape change among adults of different sizes.

Body width and depth, in larvae, grow most rapidly posteriorly. Continuing anteriorly, width growth remains rapid while depth growth declines along the body, then increases at the pectoral and head regions. 


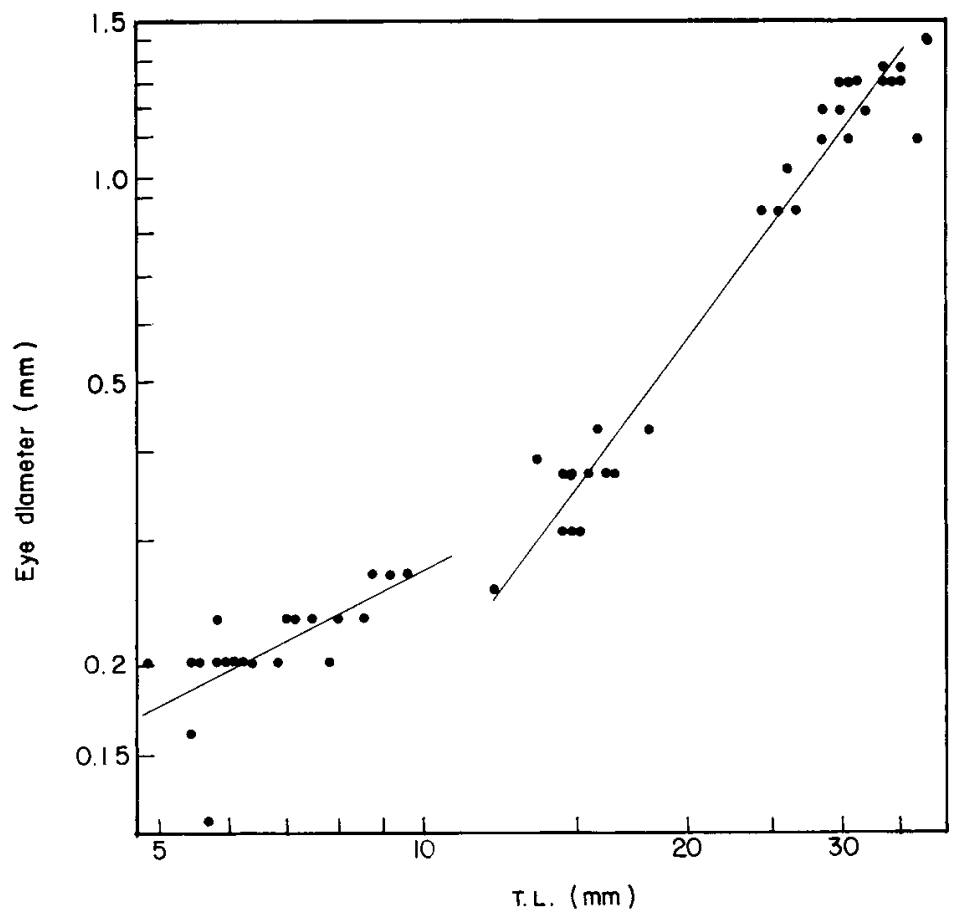

FIG. 3. Relationship between eye diameter and T.L. for Osmerus mordax, showing the unusual occurrence of two growth stanzas within the larval period. Data are plotted on a double logarithmic grid.

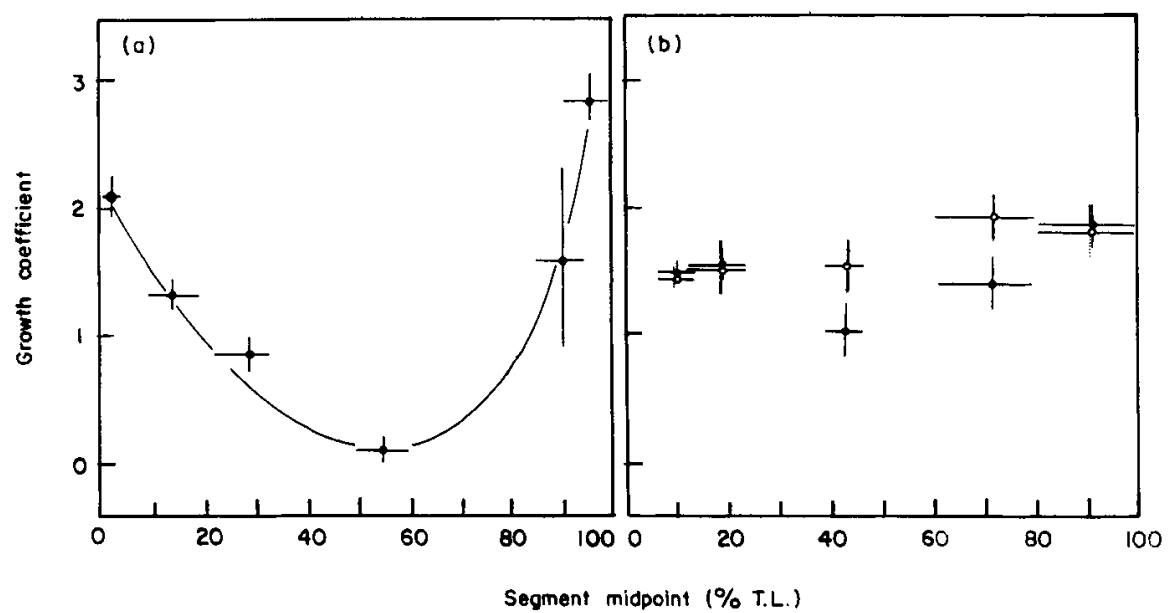

FIG. 4. Growth profiles for (a) longitudinally measured segment lengths, and (b) body depths (closed circles) and widths (open circles) in Catostomus latipinnis larvae (10-27 mm T.L.).

Fastest growth in all three planes occurs in the caudal region and is involved in the development of locomotory apparatus. Rapid growth posteriorly increases the propulsive surface area by lengthening and deepening the caudal fin and peduncle. Accelerated growth in depth and width represents increased volume, 
and perhaps cross-sectional area, of propulsive musculature in the caudal region and concomitant production of thrust forces. The ability to swim early in life is an obvious advantage to these typically nonmotile forms, enabling them to make a directed effort to avoid predators or to attack prey, thereby enhancing their survival.

Growth of the head is also emphasized, though not as much as that of the tail. This may be attributable to early elaboration of feeding and sensory mechanisms. Additionally, rapid expansion of the opercular chamber and elaboration of branchial apparatus may be signalling increased reliance upon the gills for respiration and lessening dependence upon cutaneous circulatory apparatus or other larval respiratory organs (Balon, 1977; Liem, 1981).

The presence of the U-shaped growth gradient in the larvae of all species investigated invites generalization. The larval habitat (marine or freshwater) appears to have little influence on the growth profile. Raw data used in this study were from four primary freshwater fishes (not including Osmerus mordax which is anadromous, although data were from a landlocked population). Growth profiles constructed from summarized data taken from the literature included marine and freshwater fishes. The general shape of the species may determine the shape of the gradient. Most of the species examined are filiform as larvae and elongate as adults. Micropterus dolomnieui is the notable exception (Hardy, 1978). None of the species studied exhibits specialized morphological stages (e.g. the acronurus of acanthurids, ammocoetes of petromyzontids, leptocephalus of anguilliforms and elopiforms) or behavioural stages (e.g. benthic larva of pleuronectiforms) which involve abrupt metamorphoses. Such sudden changes would be expected to affect growth of the entire body and perhaps result from an entirely different type of growth gradient.

I thank Messrs J. E. Cooper and D. E. Snyder for permitting me to make use of morphometric measurements made by them. Dr D. J. Jude, Great Lakes Research Division, University of Michigan, kindly provided facilities for data analysis. I sincerely appreciate the advice of the many individuals who have listened to, or read and commented on various versions of this paper.

\section{References}

Balon, E. K. (1977). Early ontogeny of Labeotropheus Ahl, 1927 (Mbuna, Cichlidae, Lake Malawi), with a discussion of advanced protective styles in fish reproduction and development. Env. Biol. Fish. 2, 147-176.

Cooper, J. E. (1978a). Eggs and larvae of the logperch, Percina caprodes (Rafinesque). Am. Midl. Nat. 99, 257-269.

Cooper, J. E. (1978b). Identification of eggs, larvae, and juveniles of the rainbow smeit, Osmerus mordax, with comparison to larval alewife, Alosa pseudoharengus, and gizzard shad, Dorosoma cepedianum. Trans. Am. Fish. Soc. 107, 56-62.

Doan, K. (1939). Growth of bass fry. Copeia 1939, 81-87.

Ford, E. (1930). Herring investigations at Plymouth. VIII. The transition from larva to adolescent. J. mar. biol. Ass. U.K. 16, 723-752.

Ford, E. (1931). Growth in length during the transition from larva to adolescent in the pilchard and sprat. J. mar. biol. Ass. U.K. 17, 977-985.

Franklin, D. R. \& Smith, L. L., Jr (1960). Notes on the early growth and allometry of the northern pike, Esox lucius L. Copeia 1960, 143-144.

Fuiman, L. A. (1979). Descriptions and comparisons of catostomid fish larvae: northern Atlantic drainage species. Trans. Am. Fish. Soc., 108, 560-603. 
Fuiman, L. A. \& Baker, J. P. (1981). Larval stages of the lake chub, Couesius plumbeus. Can. J. Zool. 59, $218-224$.

Hardy, J. D., Jr (1978). Development of Fishes of the Mid-Atlantic Bight, an Atlas of Egg, Larval and Juvenile Stages. Volume III, Aphredoderidae through Rachycentridae. Washington, D.C.: U.S. Fish and Wildl. Serv., Biol. Serv. Prog., FWS/0BS-78/12.

Huxley, J. S. (1931). Notes on differential growth. Am. Nat. 65, 289-315.

Huxley, J. S. (1932). Problems of Relative Growth. London: Methuen \& Co.

Liem, K. F. (1981). Larvae of air-breathing fishes as countercurrent flow devices in hypoxic environments. Science 211, 1177-1179.

Snyder, D. E. (1981). Contributions to a guide to the cypriniform fish larvae of the upper Colorado River system in Colorado. Bur. Land Mgmt, Biol. Sci. Ser. 3.

Snyder, D. E., Snyder, M. B. M. \& Douglas, S. C. (1977). Identification of golden shiner, Notemigonus crysoleucas, spotfin shiner, Notropis spilopterus, and fathead minnow, Pimephales promelas, larvae. J. Fish. Res. Bd Can. 34, 1397-1409. 